\title{
Focal and nonfocal processing of color and form *
}

\author{
SHIRLEY C. PEEKE and GEORGE C. STONE \\ Langley Porter Veuropsichiatric Institute, Liniversity of California. San Francisco. California 94122
}

\begin{abstract}
Response latencies to color are usually shorter than those to form, but sometimes this difference is absent or reversed. Three experiments investigated whether these differences result from differential susceptibility of color and form to extrafocal processing. Experiment I showed shorter same-difference latencies to color than to form when two stimuli were presented simultaneously. This difference disappeared or reversed when the two stimuli appeared sequentially. Experiment II, using a multistimulus matching task, found that differences between response latencies to form and color were minimal at the center of the display and increased peripherally. Experiment III showed that eye movements were more frequent in matching forms than colors. Tasks that produced many eve movements had long average latencies, but the relationship between eye movements and latency was not a simple one. There was evidence both for parallel and serial strategies in the use of the eyes to gather information. The results of these experiments are considered in relation to a theory of distributed attention.
\end{abstract}

Much recent research concerned with processing information in colored stimuli and geometric forms suggests that there are differences in the manner in which the human processor copes with these two types of stimuli. The reason for these differences cannot be traced to the specific stimulus sets employed, since a variety of stimulus sizes, shapes, degrees of brightness, and discriminability have been used. The results reported often suggest that the color stimuli are more noticeable or attention-capturing than the form stimuli. For example, Stone (1971a) has found a much greater effect of irrelevant color on form processing (RTs slowed by $60.120 \mathrm{msec}$ ) than of irrelevant form on color processing (RTs slowed by $10.30 \mathrm{msec}$ ). indicating that most $\mathrm{S}_{\mathrm{s}}$ had difficulty ignoring color when it was irrelevant. Lappin (1967), in a study of stimulus identification with multidimensional displays, suggested that color stimuli might be "psychologically more potent" than form stimuli and might be more readily encoded by the perceptual system.

Many studies indicate that response latencies to color stimuli are shorter than latencies to form stimuli, at least when unidimensional stimuli are being considered (Egeth, 1966: Hawkins, 1969; Stone, 1971a,b). However. Stone and Peeke (1971) found that the relative speed of color and form processing depends on the type of task being used. They presented three task formats: (1) matching-to-sample (MTS), where one of four simultaneously presented stimuli is matched to a sample previously presented: (2) oddity $(0)$, where the unique or odd stimulus is selected from four stimuli that are presented simultaneously: and (3) same-different (S-D), where two stimuli are presented sequentially and the decision "same" or "different" is made to the second stimulus. They found that color stimuli produced

\footnotetext{
*This research was supported in part by National Institute of Mental Health Research Grant $\mathrm{MH} 18146$ and in part from General Research and Support Grant FR 05550 from the National Institutes of Health. L'S. Public Health Serice to the Langley Porter Veuropsychiatric Institute.
}

shorter RTs than form stimuli in the MTS and O tasks, but on the S-D task the reverse was true. The results of this S-D task are contrary to the results of similar S-D tasks reported by others (Egeth, 1966; Hawkins, 1969). who found that color stimuli produced shorter RTs than form stimuli.

In examining the task characteristics from these S-D studies, it is seen that in the Egeth and Hawkins studies, the two stimuli to be compared were presented simultaneously, whereas in the Stone and Peeke study, the two stimuli to be compared were presented sequentially. This difference in procedure may be responsible for the difference in results concerning relative speed of color and form processing. If so, it would appear that among the tasks discussed (MTS, O. S-D) simultaneous stimulus presentations produce shorter RTs for color than for form stimuli, whereas sequential stimulus presentations have the reverse effect.

The means by which simultaneous stimulus presentations could result in shorter latencies to color stimuli than to form stimuli is suggested by Neisser's (1967) distinction between "preattentive processes" and "focal attention." The "preattentive processes" are thought to engage in preliminary "global" analysis of stimuli and to direct the "focal processes" toward those stimuli requiring more detailed analysis. These "preattentive processes" are considered to operate at least partially in parallel and to be able to control motor movements as well. This interpretation was expanded in a study by Ellis and Chase (1971) in which color discrimination and item recognition were found to occur in parallel. They suggested that color attributes can be processed at an early preattentive stage which operates in parallel with the focused attention stage. and that most form attributes (excepting gross attributes such as sizes) require focused attention for discrimination. If such is the case. then when two colors are presented simultaneously. one could be processed with focused attention while the other is processed. at least to some extent, preattentively. thus shortening processing time. If this preattentive processing occurred more with colo: 
stimuli than with form stimuli, the result would be a latency advantage for color stimuli. If two stimuli are presented sequentially, however, each one could receive focal attention and hence no latency advantage for stimuli processed preattentively.

The distinction between preattentive processing and focused-attention processing can be related to the distinction between processing of stimuli which fall upon the fovea and those which fall upon nonfoveal areas of the retina. Studies of eye movements made during a task involving visual search and pattern discrimination (Gould \& Dill, 1969) indicate that stimuli can be discriminated grossly in the periphery of the eye and only require foveal foxation for finer discriminations. A related study by Williams (1967) found that $S$ s selected objects in the extrafoveal field much better on the basis of color than on the basis of size or shape. Trevarthen (1968), in studies with primates, has suggested that two different (perhaps anatomically distinct) kinds of vision may be employed, one for patterned stimuli and one for brightness or color stimuli. From the results of Williams's study, one would expect that in a task in which several stimuli were presented extrafoveally, color stimuli would require fewer eye movements for processing than would form stimuli, since color stimuli are more amenable to peripheral processing.

In the present study, it was hypothesized that when several stimuli can be processed simultaneously, the tendency to use peripheral and focal processing in parallel will be greater for color stimuli than for form stimuli. This hypothesis was tested in several ways: Experiment I compared RTs to color and form stimuli in two S-D tasks, one where the two stimuli were presented simultaneously and one where the two stimuli were presented sequentially. It was predicted that RTs to color stimuli would be shorter than RTs to form stimuli in the simultaneous task but not in the sequential task.

Experiment II presented the MTS task used in the Stone and Peeke (1971) study with color and form stimuli; however, responses were analyzed according to location of the stimulus in the display. It was predicted that the difference between color and form RTs would be greater for the peripheral stimulus positions, where color stimuli could profit from preattentive processing, than for the central stimulus position.

Experiment III examined the number and pattern of eye movements made while performing the MTS task. It was predicted that stimuli that could be processed peripherally would require fewer eye movements than those requiring focal attention, and that those stimulus locations showing the greatest difference between color and form latencies would also show the greatest difference between color and form in number of eye movements. In addition, we sought a linear relationship between magnitude of RT and number of eye movements (with stimulus type and position held constant), which would imply that the RT consisted of components representing eye movement times as well as components representing processing times.

\section{GENERAL METHOD}

\section{Subjects}

The Ss were recruited from the staff and students of the University of California and San Francisco State College. They ranged in age from 19 to 30 years and had normal color vision. These Ss were members of a panel which was tested weekly on the same apparatus in other tasks for a period of 4 months prior to this study and hence were highly familiar with the general testing procedure and experienced in reaction time tasks. Each session was approximately $1 \mathrm{~h}$ in length, and the $\mathrm{Ss}$ were paid for participating.

\section{Apparatus}

The tasks were presented on the Visual Display Programmer, a large console at which $S$ sat. In a horizontal row on a sloping panel were arranged the five stimulus cells (Industrial Electronic Engineers, Inline Display Cells, Series 10000) spaced $7.6 \mathrm{~cm}$ apart from center to center. When the $S$ was seated $40 \mathrm{~cm}$ from the panel, the five display cells subtended a visual angle of $23.5 \mathrm{deg}$ and each stimulus subtended an angle of 2.5-3.5 deg. Each stimulus cell (referred to as $D_{1}$ to $D_{5}$ from left to right) was covered by a transparent response panel $7.6 \mathrm{~cm} \mathrm{sq}$, referred to as $R_{1}$ to $R_{3}$. Five centimeters below $R_{3}$ was another response panel, $R_{6}$, which had no stimulus display behind it. The presentation of stimuli and control of the contingencies of the experiment were provided by a block tape reader and associated circuitry. Each response produced a record on magnetic tape, together with its latency to the nearest millisecond.

\section{Stimuli}

Each color stimulus consisted of a circular patch. $27 \mathrm{~mm}$ in diam, of one of four colors (red. green, blue, or yellow). Each form stimulus consisted of one of four white geometric outlines (square, triangle, circle, or plus sign), approximately $20 \mathrm{~mm}$ in largest dimension, centered on a dark background.

\section{Procedure}

In the sequential $S-D$ task, each trial began with the first stimulus in $D_{3}$. When $S$ pressed $R_{6}$, the first stimulus disappeared, to be replaced after $180 \mathrm{msec}$ by a comparison stimulus in $D_{3}$. The $S$ pressed $R_{3}$ if the comparison stimulus was the same as the first stimulus and pressed $R_{4}$ if it was different. In the simultaneous $S-D$ task, each trial began with $S$ pressing $R_{6}$, which was followed $180 \mathrm{msec}$ later by the appearance of two stimuli, one in $D_{3}$ and one in $D_{4}$. The $S$ pressed $R_{3}$ if the two stimuli were the same and $R_{4}$ if they were different. In the MTS task, the sample stimulus appeared in $D_{1}$. When $S$ pressed $R_{6}$, four comparison stimuli appeared in $D_{2}$ to $D_{5}$. The task was to press the one that matched the sample stimulus. The sample for the next trial was presented $180 \mathrm{msec}$ after the correct response. In all tasks, a correct response caused the stimuli to disappear. An incorrect response was recorded but had no effect on the display.

\section{EXPERIMENT I}

This experiment compared reaction times to color and form stimuli in two S-D tasks, one in which the stimuli to be compared were presented sequentially and one in which the stimuli were presented simultaneously. It was 
predicted that RTs to color stimuli would be shorter than RTs to form stimuli in the simultaneous task but not in the sequential task due to a tendency for color stimuli to be processed both preattentively and focally to a greater extent than form stimuli in the simultaneous task.

\section{Method}

Four women and four men served as $\mathrm{Ss}$ for this experiment. Each $S$ received both tasks (simultaneous S-D and sequential S-D) in separate sessions. The order of task presentation was counterbalanced between Ss. Each task format consisted of 20 24-trial blocks, each block consisting entirely of color stimuli or of form stimuli. Two blocks of each stimulus type occurred in each 4-block sequence. the order within a 4-block sequence being determined randomly. The first 4 blocks were used for practice, and the remaining 16 blocks were test blocks. The selection of stimuli on each trial was random. with the restriction that $50 \%$ of the trials on each S-D task required a "same" decision.

\section{Results}

Median latencies for the "same" and "different" responses for each of the eight test blocks of color stimuli and eight test blocks of form stimuli were obtained for each of the two S-D tasks. Means of these medians (combining Ss and blocks of each stimulus type) are presented in Table 1 . An analysis of variance was performed on these data using a multifactor repeated measurements design with task (simultaneous vs sequential), response type (same vs different). stimulus type (color vs form), and blocks as within-Ss variables. Results of this analysis indicated that the two tasks were highly different $[F(1,7)=60.6, p<.01]$. A significant Task by Response Type interaction $[F(1.7)=$ 16.4, $\mathrm{p}<.01]$ and a significant Task by Stimulus Ty pe interaction $[F(1,7)=16.4, p<.01]$ were also present.

The mean RTs for the sequential task were much shorter than for the simultaneous task $(418 \mathrm{msec}$ vs $509 \mathrm{msec}$ ), as would be expected, since the first stimulus can be processed prior to the onset of the second stimulus in the sequential task so that its processing time is not part of the RT. Every S displayed this effect.

The significant Task by Response Type interaction is due to the occurrence of a faster "same" response than "different" response for the sequential task (402 msec vs $434 \mathrm{msec}$ ) but not for the simultaneous task $(511 \mathrm{msec}$ vs $506 \mathrm{msec}$ ). A Newman-Keuls test indicated significant differences in the former comparison but not in the latter comparison. Seven of the eight Ss were faster on the "same" judgment in the sequential condition. while six of the eight were faster on the "different" judgment in the simultaneous condition.

The Task by Stimulus Type interaction is clarified by examining the means in Table 1. It can be seen that. regardless of response type. the mean RT for color is shorter than the mean RT for forms in the simultaneous task (but only for five of eight Ss). while the opposite
Table 1

Mean Latencies (Milliseconds) Averaged Over Blocks for the "Same" and "Different" Responses for Color (C) and Form (F) Stimuli for tive Simultaneous and Sequential S-D Tasks Presented Separately for Each S

\begin{tabular}{|c|c|c|c|c|c|c|c|c|}
\hline \multirow[b]{3}{*}{$S$} & \multicolumn{4}{|c|}{ Simultaneous } & \multicolumn{4}{|c|}{ Sequential } \\
\hline & \multicolumn{2}{|c|}{ Same } & \multicolumn{2}{|c|}{ Different } & \multicolumn{2}{|c|}{ Same } & \multicolumn{2}{|c|}{ Different } \\
\hline & $\mathrm{C}$ & $\mathrm{F}$ & $\mathrm{C}$ & $\mathrm{F}$ & $\mathrm{C}$ & $\mathrm{F}$ & C & $\mathrm{F}$ \\
\hline 3005 & 482 & 541 & 467 & 513 & 383 & 347 & 416 & 382 \\
\hline 4056 & 426 & 454 & 419 & 455 & 423 & 402 & 420 & 375 \\
\hline 25025 & 497 & 528 & 558 & 565 & 418 & 404 & 476 & 441 \\
\hline 24050 & 493 & 524 & 483 & 506 & 372 & 354 & 395 & 369 \\
\hline 25026 & 504 & 504 & +88 & 480 & 412 & 405 & 449 & 434 \\
\hline 4060 & 534 & 521 & 502 & 465 & 384 & 389 & 406 & 364 \\
\hline 24061 & 532 & 520 & 519 & 531 & 454 & 398 & 511 & 477 \\
\hline 4061 & 552 & 567 & 573 & 580 & 477 & 404 & 539 & 485 \\
\hline Mean & 502 & $520^{*}$ & 501 & 512 & 415 & $388^{*}$ & 452 & 416 \\
\hline
\end{tabular}

Note-Ss with identification numbers below 20000 are female. ${ }^{*} p<.05 \quad$ tp $<.01$

result is obtained for every $\mathrm{S}$ in the sequential task. In the simultaneous task, the RT to color was significantly shorter (by t test for paired observations) than the RT to form for "same" responses $(t=2.74, p<.05 . \mathrm{df}=7$ ) although not for the "different" response. For the sequential task. RTs to color were significantly longer than to forms for both "same" and "different" responses $(t=3.18, p<.05$. $d f=7$. for the "same" response: $t=8.48 . p<.01, \mathrm{df}=7$, for the "different" response.)

\section{Discussion}

These results support the hypothesis that the discrepancy in results between Hawkins (1969) and Stone \& Peeke (1971) with regard to the relative latencies to color and form stimuli is due to the type of stimulus presentation. In both studies, simultaneous presentations led to faster RTs to color than to form stimuli for the "same" decision, although, unlike Hawkins. we found no difference in latency to the two stimuli for the "different" decision. Sequential presentations led to faster RTs to form than to color stimuli in both "same" and "different" decisions in the present study as well as in Stone and Peeke (1971). These results support the notion that the $S$ is capable of engaging in more preattentive processing of color stimuli during simultaneous stimulus presentations than can be accomplished with forms.

The greater magnitude of the difference between color and form RTs in Hawkins's simultaneous task than in our comparable task can probably be explained by the difference in the type of form stimuli used in the two studies. Hawkins used trapezoids with different lengths of base. which probably represented a more difficult discrimination than the familiar forms of the present study.

The reason that fom latencies were faster than color 
Table 2

Mean Latencies (Milliseconds), Averaged Over Session and Blocks, to Color (C) and Form (F) and the Difference Betwoen Them for Each Stimulus Position in the Matching-to-Sample Task Presented Separately for Each S

\begin{tabular}{|c|c|c|c|c|c|c|c|c|c|c|c|c|}
\hline S & \multicolumn{3}{|c|}{ Position 2} & \multicolumn{3}{|c|}{ Position 3} & \multicolumn{3}{|c|}{ Position 4} & \multicolumn{3}{|c|}{ Position 5} \\
\hline $\begin{array}{r}3005 \\
4060 \\
5031 \\
4046 \\
4056 \\
24050\end{array}$ & $\begin{array}{l}406 \\
456 \\
452 \\
553 \\
442 \\
476\end{array}$ & $\begin{array}{l}440 \\
465 \\
506 \\
652 \\
525 \\
465\end{array}$ & $\begin{array}{r}34 \\
9 \\
54 \\
99 \\
83 \\
-11\end{array}$ & $\begin{array}{l}385 \\
385 \\
380 \\
492 \\
408 \\
390\end{array}$ & $\begin{array}{l}410 \\
395 \\
406 \\
501 \\
411 \\
393\end{array}$ & $\begin{array}{r}25 \\
11 \\
26 \\
9 \\
3 \\
3\end{array}$ & $\begin{array}{l}405 \\
403 \\
439 \\
504 \\
411 \\
425\end{array}$ & $\begin{array}{l}467 \\
442 \\
488 \\
565 \\
494 \\
408\end{array}$ & $\begin{array}{r}62 \\
39 \\
49 \\
61 \\
83 \\
-17\end{array}$ & $\begin{array}{l}473 \\
518 \\
488 \\
629 \\
520 \\
515\end{array}$ & $\begin{array}{l}573 \\
589 \\
611 \\
767 \\
642 \\
528\end{array}$ & $\begin{array}{r}100 \\
71 \\
123 \\
138 \\
122 \\
13\end{array}$ \\
\hline
\end{tabular}

${ }^{*} p<.05 \quad+p<.01$

latencies in the sequential S-D task is not readily apparent, but was also reported in Stone and Peeke (1971), who ruled out several simple explanations.

It is important to note that the magnitude of difference in RT to the two stimulus types is quite variable for individual Ss, especially in the simultaneous task, and for some Ss the difference is very slight and even reversed. Such results suggest that different processing strategies are available to individual Ss, especially in the simultaneous task.

The finding of no difference in latency between "same" and "different" responses for the simultaneous task is in agreement with the results of Hawkins (1969) and Grill (1971) for unidimensional stimuli. The finding that "same" decisions are faster than "different" decisions in the sequential task has also been reported by Posner and Boies (1971) for physical matches and by Stone and Peeke (1971), although unpublished observations from our laboratory suggest that this difference tends to diminish with practice. Such a practice effect might also explain the results of Grill (1971), who found no difference between "same" and "different" decisions in a sequential task when the data were averaged over 9 days of practice.

\section{EXPERIMENT II}

A consistent finding in previous studies using the MTS task is that latencies are shorter to color stimuli than they are to form stimuli (Stone, 1969, 1971a, b; Stone \& Peeke, 1971). It has also been noted previously (Stone, 1970) that latencies vary in the MTS task as a function of the stimulus location. Latencies are usually shortest for stimuli located in the center of the stimulus display and are longer for stimuli to the left or right of the center. This difference in latencies at different stimulus positions could be due to two factors, information processing time and motor response time. However, unpublished observations from our laboratory indicate that the difference in motor response time for the most central and most peripheral positions is only 10-15 msec. Thus, when latency differences in excess of this amount are seen, information processing factors must be responsible.
The purpose of this experiment, then, was to examine latencies to color and form stimuli in the MTS task as a function of stimulus position.

\section{Method}

Five women and one man served as $S$ s for this experiment. Each $S$ received the MTS task with color and form stimuli for six sessions. The task format for each session consisted of 12 24-trial blocks, 3 blocks containing color stimuli, 3 blocks containing form stimuli, and 6 blocks consisting of combinations of color and form stimuli (which will be discussed in another paper). The location of the matching stimulus was determined randomly. One block of each stimulus type occurred in each 4-block sequence, the order within each 4-block sequence being determined randomly.

\section{Results}

Median latencies for each block of each stimulus type at each position were obtained separately for each $S$ on each session. An analysis of variance was performed on these data, using a multifactor repeated measurements design with sessions, location of the matching stimulus (position), stimulus type (color vs form), and blocks as within-Ss variables. Means of the medians (combining Ss, blocks, and sessions) are presented in Table 2. Mean differences between the two stimulus types (color and form) are also presented in Table 2.

The analysis indicated a significant difference among stimulus positions $[\mathrm{F}(3,15)=84.1, \mathrm{p}<.01], \mathrm{a}$ significant difference between stimulus types $[F(1,5)=$ $16.4, p<.01]$, with the mean color RT shorter than the mean form RT, and a significant blocks effect $[F(2,10)$ $=7.6, p<.01]$, reflecting a slight increase in latencies across the session. In addition, a significant interaction was obtained for Stimulus Positions by Stimulus Types $[F(3,15)=13.1, p<.01]$. The sessions effect did not reach significance.

Examination of the means for stimulus position (averaged over stimulus types) indicates that stimuli in Position $\mathrm{D}_{3}$ were processed most rapidly $(413 \mathrm{msec})$, followed by stimuli in Positions $\mathrm{D}_{4}$ and $\mathrm{D}_{2}$ (454 and $487 \mathrm{msec}$ ) and finally Position $\mathrm{D}_{5}$ (571 msec). A Newman-Keuls test indicated that each position differed significantly from each other position in latency 
( $p<.01$, all comparisons). Examination of the means for Stimulus Type by Stimulus Position indicates that color and form stimuli were processed at nearly the same speed at Position $D_{3}(F-C=12 \mathrm{msec}$ ), that color was somewhat faster than form at Positions $D_{4}$ and $D_{2}$ ( $F-C=46 \mathrm{msec}$ for $D_{4}$ and $45 \mathrm{msec}$ for $D_{2}$ ), and that color was much faster than form at Position $D_{5}(F-C=$ $94 \mathrm{msec}$ ). The differences between color and form RTs at each position were significant ( $t$ test, paired observations) $\left(\mathrm{t}=2.97, \mathrm{p}<.05\right.$ for $\mathrm{D}_{2} ; \mathrm{t}=3.04, \mathrm{p}<.05$ for $D_{3}: t=4.83, p<.01$ for $D_{4} ; t=5.00, p<.01$ for $\mathrm{D}_{5} ; \mathrm{df}=5$ all tests).

The data for individual Ss tend to agree with the results obtained for the group averages insofar as color stimuli produced shorter latencies than did form stimuli at all positions for five of six Ss, and the magnitude of the difference between latencies to color and form increased in the periphery for each individual as well, especially at Position $D_{5}$. Although large differences between individuals are present in the magnitude of the $\mathrm{F}-\mathrm{C}$ difference at each position, the rank order of RTs across stimulus positions was the same for each individual for color stimuli and for all but one $S$ for form stimuli, indicating some similarity in the processing of the two stimuli.

\section{Discussion}

The results indicate that in the MTS task the difference between color and form latencies varies systematically from position to position; that at the central position $\left(D_{3}\right)$, latencies to form and color differ slightly, but the more peripheral the position, the greater the latency advantage for color relative to form stimuli; that the rank order of positions in terms of speed is similar for both stimulus types.

Considering that colors and forms can be processed at close to the same speed on $\mathrm{D}_{3}$, a difference as large as that seen between color and form on Position $\mathrm{D}_{5}$ cannot be explained in terms of differences in brightness, or discriminability, or motor response time and must, therefore, indicate a difference in the speed with which colors and forms can be processed in the peripheral portions of the display. Such a difference might indicate a differential capacity for preattentive processing with colors and forms, which could be brought about by an increased need for fine discrimination in processing each form stimulus. Such fine discrimination would demand greater attention (or processing capacity) and, according to recent notions of distributed processing energies (Taylor et al, 1967; Moray, 1967: Atkinson et al, 1969), would then leave less attention, or processing capacity, available for the task of preattentive processing.

The results of Experiment I might have led us to expect that RTs to form would be faster than those to color at $D_{3}$, if this location is uniformly treated first by Ss. The small, but consistent, advantage for color over form suggests that $S$ s are variable as to which stimulus is fixated first.
Even if processes such as comparing and testing could not be done for more than one stimulus at a time. the capacity to search and encode more than one stimulus at a time would still provide for reduced latencies compared with latencies obtained when processing was entirely serial. Exarnination of frequency and patterning of eye movements for each stimulus position would be expected to provide more information as to the reason for the observed difference in response latency to color and form stimuli in different stimulus positions.

\section{EXPERIMENT III}

The ability to Ss to extract a limited amount of information from stimuli which are not being fixated (i.e., stimuli which project outside of the foveal area of the retina) has been reported by Sanders (1970), Gould and Dill (1969), and Williams (1967). In the study by Gould and Dill, Ss determined how many of the eight test patterns matched a standard pattern while frequency and duration of eye fixations were recorded. Patterns that were highly different from the standard pattern were not fixated foveally and were presumably rejected while the $S$ fixated an adjacent pattern. The more similar a test pattern was to the standard pattern, the greater the probability of its being fixated. From examining the spatial characteristics of the eye fixations, these authors concluded that "while $\mathrm{S}$ was looking directly at the standard he was also processing information about peripheral patterns [p. 318]." Williams (1967) refers to this process as "acquisition," which he defines as the "selection of a new object from the extrafoveal field to fixate and the movement of the eyes to actually fixate that object [p.355]." Gould and Dill further suggest that under certain conditions, the precise foveal feature analysis of the fixated pattern operates in parallel with gross feature analysis of other patterns occurring in the periphery. A similar conclusion was reached by Stone (1970), who reported that "some information about the location of the matching stimulus was gained before or during the first fixation shift ... [p. 203]."

From these studies, it was hypothesized that, in an MTS task with four simultaneous alternative stimuli. color stimuli can be discriminated by means of gross feature analysis more readily than the form stimuli and require fewer eye fixations for successful discrimination than form stimuli. It would follow from this hypothesis that the difference in number of eye fixations for color and form stimuli should be greater when the matching stimulus is in the periphery of the display than when it is in the central portion of the display. It was predicted that the differences in RT observed between color and form at each stimulus position would be related to the difference in the number of eye movements required to make the decision.

Method

Three women and wo nen served as Si for this experiment. 

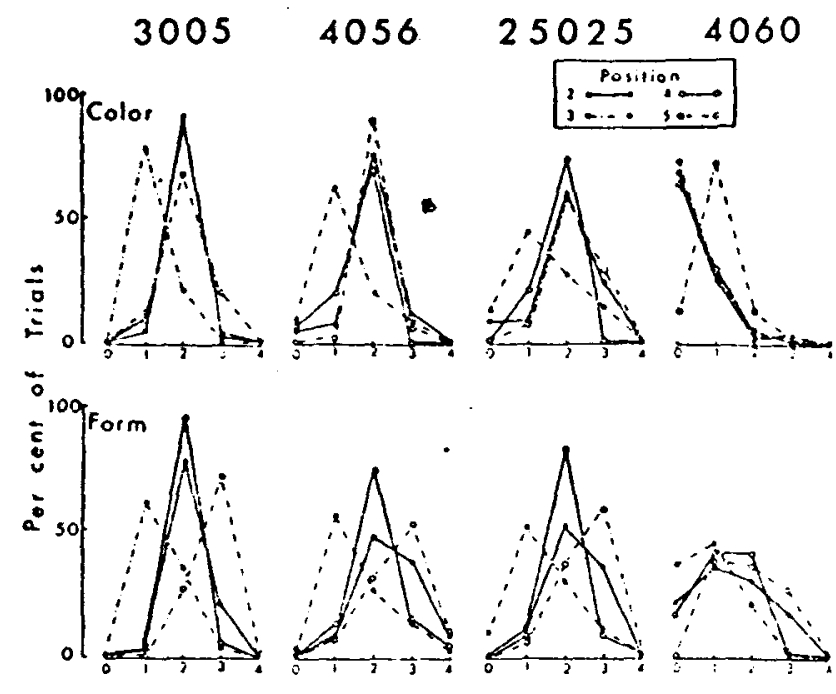

Eye Movements. Per Trial.

Each $S$ received 20 blocks of color stimuli and 20 blocks of form stimuli in a single session of the MTS task. Each block contained 12 trials, with location of the matching stimulus determined randomly. Two blocks of each stimulus type occurred in each 4-block sequence, the order within the 4-block sequences being determined randomly.

Eye movements were recorded by electroculography. One Beckman skin electrode was placed at the external canthus of each eye and a third was placed between the brows. An analog recording of the eve movements was made on one channel of an Offner polygraph and a second channel recorded every response of the S. In addition. eye movements were identified as left or right by means of calibrating while the $S$ changed his focus from one stimulus position to the next.

\section{Results}

The number of right and left eye movements occurring between the $\mathrm{R}_{6}$ and the correct response were combined in each trial and categorized into one of the following five categories: $0,1,2,3,4$, or more eye movements per trial. Then trials were grouped according to the location of the matching stimulus $\left(D_{2}, D_{3}, D_{4}\right.$, $\left.D_{5}\right)$, and the percent of the total number of trials for a given stimulus location that fell into each eye-movement category were plotted separately for each $S$ and for each stimulus type (color vs form). These percentage frequency distributions are shown in Fig. 1. The five categories of eye movement are placed along the abscissa, and each stimulus location is plotted separately. For example, in the frequency distribution of color trials for $\mathrm{S} 3005$ at Position $\mathrm{D}_{3}, 1 \%$ of the trials had no eye movement, $78 \%$ of the trials had one eye movement, and $21 \%$ of the trials had two eye movements.

Three of the Ss $(3005,4056,25025)$ are fairly similar in the shape of their distributions for each stimulus position. In responding to color, these Ss tended to make one eye movement when the matching stimulus was at $D_{3}$ and two eye movements when it was at $D_{2}$, $D_{4}$, and $D_{5}$. For the same three $S s$, a correct response to a form at $D_{3}$ still requires only one eye movement on a

\section{0}

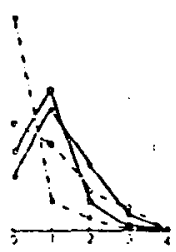

Fig. 1. Distributions for the percent of the total trials for each stimulus position that occur in each eye-movement category. Categories are number of eye movements per trial. Distributions for color stimuli are presented at the top and distributions for form stimuli are at the bottom of the figure for each $S$. majority of trials, and at $\mathrm{D}_{2}$ and $\mathrm{D}_{4}$ only two eye movements on most trials. However, a correct response to $D_{s}$ now usually requires three eye movements rather than two.

Chi squares done separately for each of these three Ss and separately for each stimulus position tend to substantiate these observations. The chi-square tables consisted of frequencies of trials categorized according to stimulus type (color vs form) and number of eye movements, with the five categories of eye movements collapsed into two categories in order to avoid the occurrence of cells with very low frequencies. Significant chi squares were found for Position $D_{5}$ for each of the three Ss $\left(\chi^{2}=36.10,33.50,8.25\right.$ for Ss 4056,3005 , and 25025 , respectively; $\mathrm{p}<.01, \mathrm{df}=1$ for all tests), indicating that at this position there were significantly more eye movements per trial for form stimuli than for color stimuli. There were no significant chi squares for Positions $D_{3}$ and $D_{4}$. Only $S 4056$ had a significant chi square at Position $\mathrm{D}_{2} \quad\left(\chi^{2}=19.09, \mathrm{p}<.01\right)$, indicating more eye movements for forms than for colors at this position for this $S$.

These three Ss showed a rather stereotyped tendency to begin each trial by looking at the sample in $D_{1}$, then pressing $R_{6}$ while making an eye movement to the right, stopping at $D_{3}$. This sequence occurred, on the average, on $93 \%$ of the trials for these Ss regardless of stimulus type. When the stimulus display came on $180 \mathrm{msec}$ after the $R_{6}$, they were fixating $D_{3}$, and if it contained the matching stimulus, they responded correctly with no other fixations $70 \%$ of the time regardless of stimulus type. If $\mathrm{D}_{3}$ did not contain the matching stimulus, these Ss made one more eye movement, either to the left (to $\mathrm{D}_{2}$ ) or to the right (to $\mathrm{D}_{4}$ ), and responded correctly without requiring an additional eye movement on $73 \%$ of the trials. Thus, when the matching stimulus was at Position $\mathrm{D}_{2}$, two eye movements tended to occur, one to the right followed by one to the left; when the matching stimulus was at Position $D_{4}$, two eye 
Table 3

Median Latencies (Milliseconds) Over Blocks for Responses to Color (C) and Form (F) Stimuli and the Difference Between Them for Each Stimulus Position in the Matching-to-Sample Task

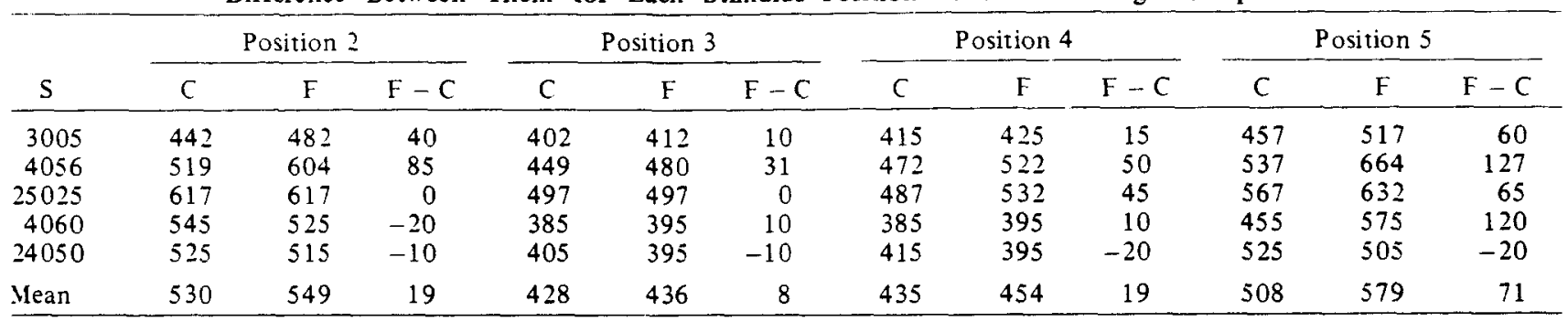

movements also tended to occur, one to the right followed by another to the right. Such economy of eye movements could come about only if, while fixating $\mathrm{D}_{3}$. the Ss were simultaneously processing some aspects of $\mathrm{D}_{2}$ and $\mathrm{D}_{4}$ to determine the direction of the next eye movement.

Examination of Table 3, which contains the median RT scores for each stimulus type at each response position and the $\mathrm{F}$ - C difference scores, indicates that all three of these Ss had fairly large F-C RT differences for Position $D_{5}(60 \mathrm{msec}$ for $3005,127 \mathrm{msec}$ for $4056.65 \mathrm{msec}$ for 25025); this F-C RT difference corresponds to the difference in number of eye movements made to color and form stimuli at $D_{5}$. Also. the $\mathrm{F}-\mathrm{C}$ RT score for Position $\mathrm{D}_{2}$ for $\mathrm{S} 4056$ was $85 \mathrm{msec}$, which corresponds to the significantly greater number of eye movements made to form than to color stimuli at this position.

The remaining two Ss (4060 and 24050) were idiosyncratic in their pattern of eye movements during the MTS task. Both Ss tended not to begin a trial by fixating the sample. but rather continued to fixate $D_{3}$ and. apparently. processed the sample peripherally. Consequently, both Ss had a high incidence of trials containing no eve movements $(37 \%$ for $4060,50 \%$ for 24050) compared with a mean of $2 \%$ for the other three Ss. These two Ss diverge from each other, however, in their performance with form stimuli. With color stimuli, S 4060 successfully responded to $D_{2}, D_{3}$, and $D_{4}$ without moving her eyes on $68 \%$ of the trials. but with form stimuli she could do so only $25 \%$ of the trials. Chi squares for this $S$ indicated a significant difference on each position in number of eye movements made for color and form stimuli $\left(\chi^{2}=24.42, \mathrm{D}_{2}: \chi^{2}=26.20 . \mathrm{D}_{4}\right.$ : $\chi^{2}=22.34, D_{5}: d f=1 . p<.01$ all positions). Although this $S$ had significantly more eye movements for form stimuli than for color stimuli on all positions, examination of Table 3 indicates that only on Position $\mathrm{D}_{5}$ did she have a large $\mathrm{F}-\mathrm{C}$ difference score for reaction time $(\mathrm{F}-\mathrm{C}=120 \mathrm{msec})$.

S 24050, on the other hand, produced very similar frequency distributions to color and form stimuli, making no eye movements when the matching stimulus was at $D_{3}$ on $84 \%$ of the color trials and $90 \%$ of the form trials, and making zero or one eye movement to
$\mathrm{D}_{2}, \mathrm{D}_{4}$, and $\mathrm{D}_{5}$ on $77 \%$ of the color trials and $89 \%$ of the form trials. Unlike the other four Ss who tended to increase their eye movements with form stimuli. S 24050 processed both types of stimuli in an almost identical way. No significant chi squares were found for any position for this S. Examination of Table 3 reveals that this S's F - C difference scores for each position were not large, indicating that his RTs to color and form were almost the same.

To summarize, for four of the five Ss, the correspondence between number of eye movements and magnitude of RT for each stimulus type at each response position was good. Ss having much larger RTs to form than to color at a position also produced more eye movements per trial at that position, except for $S 4060$. as noted above.

While these results suggest a relationship between reaction time for a particular stimulus and the number of eye movements made while processing that stimulus, they do not tell us whether or not this is a causal relationship, that is, whether long RTs are caused by the increased time required for more fixations. This interpretation implies a serial ordering of eye movements, followed by processing of the fixated stimulus, followed by another eye movement, etc.. leading to the expectation that, with stimulus type and response position held constant, the RT will increase in proportion to the number of eye movements.

To test this hypothesis, the median RT for those trials falling into each eye-movement category was obtained for each $\mathrm{S}$ for each stimulus type and position. Ss were grouped according to the two patterns of response already described. Group 1 consisted of Ss 4060 and 24050 , who tended to have 0,1 , or 2 eye movements. and Group 2 consisted of Ss 3005, 4056, and 25025. who tended to have 1,2. or 3 eye movements. Figure ? contains means (over Ss) of the medians for each group for each stimulus type and position and eye-movement category. For Group 1. it makes little difference on Positions $\mathrm{D}_{3}$ and $\mathrm{D}_{4}$ whether 0.1 , or 2 eye movements occurred, regardless of stimulus type. The same is true for $D_{2}$ and $D_{5}$ when 0 or 1 eye movement occurred but not when 2 eye movements occurred. In the latter case. RTs to $\mathrm{D}_{5}$ increased by $210 \mathrm{msec}$ for forms and by 91 msec for colors. RTs to $D_{2}$ increased by 136 msec for 


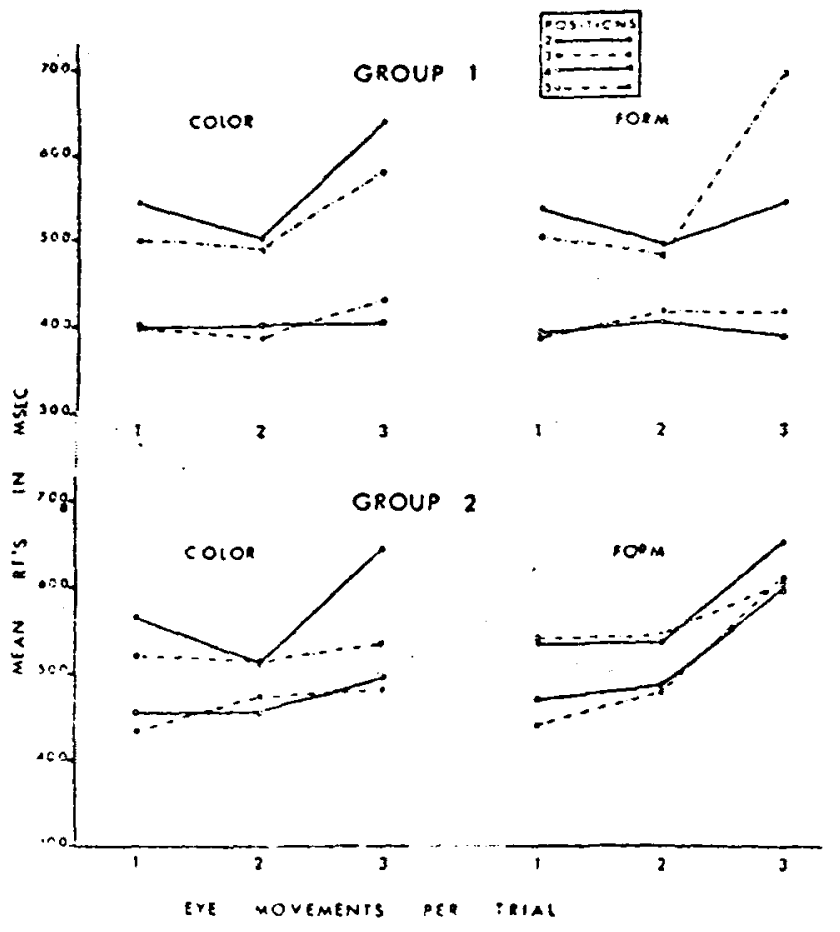

Fig. 2. Mean reaction time (milliseconds) averaged over two Ss (Group 1) and three Ss (Group 2) for responses categorized by stimulus position and number of eye movements per trial separately for color and form stimuli.

colors. For Group 2, it makes little difference whether 1 or 2 eye movements occurred, but if 3 eye movements occurred, the RT for $D_{2}$ increased by $131 \mathrm{msec}$ for colors and by $117 \mathrm{msec}$ for forms; Positions $\mathrm{D}_{3}$ and $\mathrm{D}_{4}$ also had large increases in RT to forms (129 and $110 \mathrm{msec}$ ), while $D_{5}$ increased by $58 \mathrm{msec}$. Other increases in RT did not exceed $40 \mathrm{msec}$. For both groups, the major change in RT came in the category of the greatest number of eye movements per trial. For Group 1. the effect was restricted to the peripheral positions $\left(D_{2}\right.$ and $\left.D_{5}\right)$, but this was not the case for Group 2.

What the magnitude of the increase in RT should be in order to indicate a serial ordering of eye movement followed by processing of the information followed by eye movement is difficult to determine since few studies have been concerned with fixation duration in a visual search task such as the one reported here, where the number and location of the stimuli to be searched are known in advance and where a stereotyped pattern of eye movements might be expected. Gould and Peeples (1970), using a visual search task, reported fixation durations of approximately $250 \mathrm{msec}$, and Gould and Dill (1969) found most fixations to be longer than $200 \mathrm{msec}$. However, the stimuli in these two studies were small (subtended visual angles of $1.5 \mathrm{deg}$ and 15-23 min, respectively) compared to the stimuli in the present study. Gould and Dill reported that such variables as number of elements in a pattern, whether the pattern was a target or not, and relative features of target and nontarget patterns (difticulty of discrimination) affected fixation durations. Also, they reported that $10 \%$ of the fixations were less than $150 \mathrm{msec}$ in duration. Consequently, we might cautiously entertain the hypothesis that those RT increases in excess of $100 \mathrm{msec}$ represent a largely serial ordering of eye movements and the processing of fixated information: that increases in RT of less than $40 \mathrm{msec}$ represent a largely parallel relationship between eye movements and information processing: and that increases in RT of $40.100 \mathrm{msec}$ represent a mixed strategy, parallel on some trials and serial on others.

\section{Discussion}

The results of Experiment III indicate that for four of five Ss there was a high correspondence between the number of eye movements and magnitude of RT for a given stimulus type and position, and that for four of five Ss significantly more eye movements were made for form than for color stimuli in the most peripheral position $\left(D_{5}\right)$, while for four of five Ss, no difference in number of eye movements per trial was found for the more central positions $\left(\mathrm{D}_{3}\right.$ and $\left.\mathrm{D}_{4}\right)$.

The results further suggest that the relationship between the time required to process a display containing several stimuli (as was used in this study) and the number of eye movements is complex and probably has several forms. One of these forms is the serial occurrence of eye movement followed by information processing followed by another eye movement, etc. This type of relationship occurred only with the maximum number of eye movements per trial. Another form of the relationship between RT and occurrence of eye movements has been suggested by Stone (1970), who examined RTs while eye movements varied but stimulus position remained constant and found little correspondence between duration of RT and number of eye movements. He suggested that although eye movements tend to parallel the serial processing of stimuli, they contribute little to the total latency on a trial.

One might speculate that a "program" for initiating eye movements operates in parallel with the processing of information from the previous fixation, with the eye movements timed (on the basis of experience from previous trials) so that one has just been completed by the time the focal processor is ready for more input. Judging from the fact that on most trials a matching color stimulus at Position $D_{s}$ was responded to correctly with only two eye movements, the Ss apparently were able to process at least two stimuli on each fixation. One could speculate that the long RTs to $D_{2}$ when three eye movements occurred came about because the $\mathrm{S}$ erroneously failed to detect the match in the first fixation (while processing $\mathrm{D}_{2}, \mathrm{D}_{3}$, and $\mathrm{D}_{4}$ ) and made the second fixation (to process $D_{5}$ ) according to "plan" which should have yielded the match. When it failed, a 
third eve movement was required (to rescan $D_{2}$ and $D_{3}$ ). which. because of its "unplanned" nature, was done serially.

A related type of "program" is one in which the number of eye movements to be made is preset before the trial on the basis of past experience or expectation. Such a "program" is suggested by finding in the present study that it makes little difference in magnitude of RT whether 0 or 1 eye movements took place for Group 1 or whether 1 or 2 eye movements took place for Group 2. Correct decisions for these trials could probably have been made by all Ss with only the minimum number of eye movements, provided the middle of the display was fixated. Then the additional fixation would be the result of an eye movement plan automatically preset to perform the additional eye movement regardless of the outcome of the first fixation, or might serve to confirm, while the response was being executed, a decision already made. That Ss 3005. 4056, and 25025 made their second fixation to the appropriate stimulus position on $73 \%$ of the trials in which $\mathrm{D}_{2}$ or $\mathrm{D}_{4}$ contained the matching stimulus indicates that these $\mathrm{Ss}$ had already ascertained, prior to the second fixation, the location of the matching stimulus and, consequently, that the second fixation was unnecessary. Further information regarding the role of the second fixation in these trials would come from data concerning the relationship between the time of initiation of the second fixation and the time of the motor response. If the time between these two events were very short, it would indicate that the second fixation was serving primarily for confirmation or feedback purposes. Such information, as well as information concerning the duration of each fixation, was not available in this study.

Alternatively, the $\mathrm{S}$ may have the option of performing one long-duration fixation in which two or three stimuli are processed or may choose to execute several short-duration fixations where a single stimulus is focused upon at each fixation. The S may have all of these plans in his repertoire and be able to employ them interchangeably, selecting one or another according to the task demands or a need for energy conservation, or the like.

\section{CONCLUSIONS}

The results of the three experiments reported here indicate that, as suggested by Garner (1970). understanding the nature of the stimulus is necessary to the study of information processing. In this study, we observed differences in the processing of color and form stimuli that are more complex than the simple observation that RTs are shorter to one stimulus type than to another. The color and form stimuli used in this study were processed by most Ss at virtually the same speed or with a slight advantage for form stimuli when sequential presentations of the sample stimulus and test stimulus were used in the S-D task or when the matching stimulus was in Position $D_{3}$ in the MTS task. In contrast. color stimuli had an advantage for most Ss when simultaneous presentations of the sample and test stimuli were used in the S-D task or when the matching stimulus was in Positions $D_{2}, D_{4}$, and $D_{5}$ in the MTS task.

We suggest that this difference in results is related to (1) whether or not it is advantageous to use focal and "preattentive" processing in parallel (as would be the case with simultaneous stimulus presentations). and ( 2 ) a differential capacity to discriminate colors and forms in the periphery of the retina. These results can be interpreted in terms of a "distributed attention" model which, briefly stated. hypothesizes that a finite quantity of attention is deployed over relatively fixed information structures (which perform such functions as filtering, encoding, and memory storage) so that the steps involved in input and processing of information proceed in parallel so long as enough attention is available for all the structures involved, but proceed serially (and more slowly) when some function requires essentially all of the available attention. With practice. an attention deployment plan (specific to the particular task) is adopted which determines which structures receive attention and for how long, so that attention is redeployed according to plan, allowing the information to be processed smoothly and efficiently.

In the present study, one could speculate that since the receptors in the periphery of the eye are less well equipped than those in the fovea for making the fine-grained analysis required for form discrimination. such discriminations made in the periphery would require the deployment of a large amount of attention. This large attention demand could not be met simultaneously with a form discrimination made focally and, consequently, an attention plan which is at least partially serial would be employed.

The results from the MTS task in Experiments II and III show a relationship between RT and stimulus position and between frequency of eye movements and stimulus position so that the more peripheral the stimulus position, the longer the RTs and the more eye movements made. However, such a relationship does not necessarily mean that the long RTs are caused by the increased time required for more fixations, since there may be a "program" for initiating eye movements (subordinate to the "attention-deployment plan") which operates in parallel with the processing of information from a stimulus previously focused upon. Under this "program." the eye movements ordinarily would be timed (on the basis of experience) so that one was completed just as a relevant information structure was ready to accept new information. However. under conditions of high information load, the amount of available attention would be insufficient for the peripheral scanning that seems (from this study. and from Gould \& Dill. 1969) to be necessary for the most 
efficient deployment of eye movements. Thus, the coordination of eye movements with information processing would sometimes be serial, especially during difficult discriminations or at times when the parallel program failed to turn up the matching stimulus, necessitating a more detailed search.

Of value in demonstrating the applicability of the "distributed attention" model to these data would be an empirical basis for replacing the ambiguous concept "processing" with more discrete concepts standing for the functions which are performed by information structures (such as "encoding," "feature comparison," etc.). The identification of more specific functions would presumably allow explication of the ones that tend to be executed in parallel for a specific task and information load and the ones that must be done serially. Garner (1970) has expressed a similar thought, "If we want to understand how the organism processes information, we must be prepared to ask under what circumstances a particular form of processing is used [p. 351]." The uncovering of characteristics of such functions or "processes" would also assist in accounting for the remarkable variety and degree of individual differences apparent among the Ss performing in this study.

\section{REFERENCES}

Atkinson, R. C., Holmgren, J. E., \& Juola, J. F. Processing time as influenced by the number of elements in a visual display. Perception \& Psychophysics, 1969, 6, 321-326.

Egeth. H. E. Parallel versus serial processes in multidimensional stimulus discrimination. Perception \& Psychophysics, 1969, 1, 245-252.

Ellis, S. G., \& Chase, W. G. Parallel processing in item recognition. Perception \& Psychophysics, 1971, 10, 379-384.

Garner, W. R. The stimulus in information processing. American Psychologist, 1970, 25, 350-358.

Gould, J. D., \& Dill, A. B. Eye-movement parameters and pattern discrimination. Perception \& Psychophysics, 1969, 6, 311-320.
Gould, J. D.. \& Peeples, D. R. Eye movements during visual search and discrimination of meaningless, symbol, and object patterns. Journal of Experimental Psychology, 1970, 85, $51-55$.

Grill, D. P. Variables influencing the mode of processing of complex stimuli. Perception \& Psychophysics, 1971, 10, 51-57.

Hawkins, H. L. Parallel processing in complex visual discrimination. Perception \& Psychophysics, 1969, 5, 56-64.

Lappin, J. S. Attention in the identification of stimuli in complex visual displays. Journal of Experimental Psychology, $1967,75,321-328$.

Moray, N. Where is capacity limited? A survey and model. Acta Psychologica, 1967, 27, 84-92.

Ne isser, U. Cognitive psychology. New York: Appleton-Century-Crofts, 1967.

Posner, M. I., \& Boies, S. J. Components of attention. Psychological Review, 1971, 78, 391-408.

Sanders, A. F. Some aspects of the selective process in the functional visual field. Ergonomics, 1970, 13, 101-117.

Stone, G. C. Response latencies in matching and oddity performance: Effects of format, stimulus, and demand variables. Perceptual \& Motor Skills. 1969, 29, 219-232.

Stone, G. C. Response latencies in human matching-to-sample. Perception \& Psychophysics, 1970, 7, 197-205.

Stone, G. C. Individual differences in information processing: Comparison of simple visual stimuli. Perceptual \& Motor Skills, 1971a, 33, 395-414.

Stone. G. C. Response latencies in visual search involving redundant or irrelevant information. Perception \& Psychophysics, 1971b, 9, 9-14.

Stone, G. C., \& Peeke, S. C. Stimulus characteristics, output requirements, and latencies of response to visual stimuli. Proceedings, 79 th Annual Convention, APA, 1971, 3-4.

Taylor, M. M., Lindsay, P. H., \& Forbes, S. M. Quantification of shared capacity processing in auditory and visual discrimination. Acta Psychologica, 1967, 27, 223-229.

Trevarthen. C. B. Two mechanisms of vision in primates. Psychologische Forschung, 1968, 31, 299-337.

Williams, L. G. The effect of target specification on objects fixated during visual search. Acta Psychologica, 1967, 27, 355-360.

(Received for publication December 4, 1972; revision received March 22, 1973.) 